\title{
Determinants of Receipts of Environmental Awards \& Certifications by Hotels: Experience from the Western Province in Sri Lanka
}

\author{
Kanchana Wickramasinghe \\ Institute of Policy Studies of Sri Lanka (IPS) \\ 100/20, Independence Avenue, Colombo 7
}

Tele: (94) 112143100

E-mail: kanchana@ips.lk

\begin{abstract}
This paper attempts to assess the receipts of environmental awards and certifications by the hotel sector in the Western Province of Sri Lanka and the factors determining such receipts. The assessment is based on primary data collected from the 94 registered hotels in the Western Province, using a pre-tested structured questionnaire. Key informant interviews and stakeholder discussions were carried out in formulating the questionnaire. Face-to-face interviews were conducted to collect required data. The analysis was done using the Probit approach. It shows that nearly 19 percent hotels in the sample have received environmental awards and certifications. According the econometric results, chain affiliation and the luxury level of the hotels are significant determinants of receipts of environmental awards and certifications.
\end{abstract}

KEYWORDS: Certifications, Green, Environmental awards, Hotels, Sri Lanka

\section{Introduction}

There is an increasing recognition in regard to the need and benefits in promoting sustainability aspects of tourism. This encompasses various forms of tourism and also various sub-sectors in the tourism industry. It is the high time for Sri Lanka to place itself as a sustainable tourism destination, given the prospects in terms of tourism following the end of the conflict in May 2009. According to UNWTO (2011), when the South Asian region showed an 11 percent increase in the tourist arrivals in 2011, Sri Lanka recorded remarkable growth of 48 percent. The World Travel Market 2011 Industry Report identifies Sri Lanka as one of the five emerging countries after Brazil, Russia, India, China and South Africa, due to its revival after the civil war, high investments in infrastructural development and the beauty of the destination.

In order to reap the benefits of the tourism industry boom, the government has set targets to attract 2.5 million tourists by 2016. Several initiatives are in place to cater 
to the increasing demand for hotel accommodation to the targeted number of tourist arrivals by means of new investments and expansions of existing accommodation facilities. Accordingly, the number of hotels rooms is expected to increase to 50, 000 by 2016. As at 2013, the total number of rooms in both hotels and supplementary accommodation units was 23,596 and the hotel rooms accounted for nearly 69 percent of the total number of rooms.

Accommodation sector is highly reliant on the two natural resources; namely of water and energy for its all operations and generates waste. In the case of Sri Lanka, the hospitality sector ranks as the most energy intensive and therefore faces high energy costs. Considering both economic and environmental factors, it is important that the hotel sector undertakes good environmental practices. Receipts of environmental awards and certifications can be considered as indications of adoption of good environment practices.

Good environmental management practices can result in reduced cost of operation. Further, it can also lead to increase reputation of the hotels and thereby increase the consumer demand. Awards and certifications help to reveal the environment management related information in individual hotels to its customers and other relevant stakeholders. However, there has not been any comprehensive study conducted in this regard to this.

Studies from other countries have used various approaches to measure environmental orientation in hotels. The present paper intends to assess the receipt of environmental certifications and environmental awards as an indicator of the level of environmental management in hotels in Sri Lanka. Accordingly, the specific research questions that the study intends to answer are (a) what is the level of receipts of environmental awards and certifications by hotels in Sri Lanka? (b) What are the factors determining the receipt of such awards and certifications?

\section{Factors Determining Various Environmental Management Aspects in Hotels: Empirical Evidence}

Existing literature on firms' environmental management shows that environmental protection in the corporate sector has been shifted more towards a proactive approach with internal motivations and changes in corporate culture and management practices (Khanna and Speir, 2007). Identification of a suitable indicator to measure environmental performance is important in analyzing its determinants.

Numerous approaches are used to assess environmental performance in the corporate sector including the hotels. Ethridge (1998) classifies the approaches into three categories namely, lagging indicators, leading indicators and environmental condition indicators. Lagging indicators measure the environmental performance in terms of outcome (pollution level for instance). Lagging indicators is limited in use 
due to data availability issues. Leading indicators imply in-process indicators towards environmental performance.

Previous studies have conceptualized the environmental management in the corporate sector using various approaches. However, studies which focus on actual consumption levels of energy and water and generation levels of waste are lacking in the existing literature. A large number of studies in the literature attempts to measure the environmental performance using subjective indicators such as perception, attitude etc., and using qualitative techniques such as Likert scale.

Mamingi et al. (2008) takes into consideration of environmental news in print media of firms as a factor changing the environmental performance of the firms. Klassen and McLaughlin (1996) derive different indicators to find out the impact of environmental management on firm performance. The indicators include receipts of environmental awards, emission ratio, compliance ratio, overall environmental rating ratio, environmental crisis sample, emission ratio and overall environmental rating ratio.

The focus of a number of studies has been based on Environmental Management Systems (Segarra-Oña et al., 2012). Also, another branch of literature has considered on participation in voluntary environmental programmes (Blackman et al., 2007; Rivera, 2002). There is another growing branch of literature in regard to certifications and awards (Segarra-Oña et al., 2012; Klassen and McLaughlin, 1996).

Segarra-Oña et al. (2012) shows that size of the hotel and organization characteristics have impacts on gaining positive impacts in relation to revenue in the hotels having the ISO 14001 certification. Gil et al., (2001), based on the Spanish hotel industry, measures the impact of selected hotel characteristics, such as age of facilities, size, chain affiliation on environmental performance. Hotel chains adopt standardized practices among the individual hotels which belong to them and this may be applicable to environmental management practices also. Hence, chain affiliated hotels get a number of advantages over the independent hotels. Some of the benefits of being chain affiliated hotels are, training on environmental protection techniques, methods and or activities, opportunities to be included in programs or activities already functioning or that are known to be useful, technical advice to hotels that start up such act activities and easy access to more ecological markets (Gil et al., 2001).

The present paper aims to assess the environmental orientation of hotels based on environmental awards and certifications. Following the literature, paper takes into account several hotel characteristics, such as hotel size, chain affiliation, luxury level, classification, and number of employees per room. Thus the study generates valuable and novel research-based information which are essential for development of sustainable tourism policies in Sri Lanka and elsewhere. 


\section{Study Area and Data}

\section{Study Area}

The study is based on the hotels registered with the Sri Lanka Tourism Development Authority (SLTDA) in the Western Province of Sri Lanka. The categorization of tourism accommodation units of the SLTDA includes tourist hotels, guest houses, bed \& breakfast units, restaurants, boutique villas, and establishments that offer water sports. Among them tourist hotels were selected for the present study, as they are operated in larger scale compared to other categories. Accordingly, the energy, water consumption and waste generation can be of significant importance in the tourist hotels compared to other categories.

Western Province is selected as the study area, as it shows the highest number of tourist hotels at provincial level in Sri Lanka. The districts in the Western Province, namely Colombo, Gampaha and Kalutara have around 110 hotels altogether. Highest number of hotels and the number of rooms can be found in Colombo district.

Primary data for the study was collected through a survey, using structured questionnaire. The questionnaire was pre-tested and fine-tuned based on the interviews with the key experts in the tourism, energy, waste and water sectors of Sri Lanka.

\section{Sample Characteristics}

According to the list of registered hotels obtained from the SLTDA, the number of hotels is 110 . However, while undertaking the survey it was revealed that 16 hotels have to be removed from the sample as they were identified as not functioning during the survey period. Therefore, out of the 94 hotels available for the survey, only 78 percent hotels participated in the survey, recording a response rate of 83 percent. This seems to be a satisfactory response rate compared to the rates of the previous studies.

The survey included several steps. In the first round hotels were contacted to identify the officer who is responsible for environmental management and collect his contact details. In the second round, the identified officers were contacted and the purpose of the survey was explained and formal request letters were sent. Based on the appointments, the trained enumerators visited the hotels to conduct face-toface interviews. For most of the hotels, the same hotel had to be visited more than one time, as the respondents could not give their records on energy, water, waste and performance indicators during the first visit. Also, a several round of telephone calls had to be made in getting the appointments and following up to collect missing data. 
Sample represents around 40 percent of the small hotels, of which the number of rooms is less than 50. The rest of the hotels belong to large hotel category. The average number of rooms of the hotels in the sample is 83 . Around 68 percent of the hotels have a star rating. Of the star rated hotels, the percentages of hotels under one, two, three, four and five star ratings are respectively 15, 13, 21, 28 and 22 percent. The size of the hotels (in terms of number rooms) increases as star rating increases. Under luxury level 42 and 40 percent of hotels respectively are luxury and mid-range hotels. Nearly half (49 percent) of the hotels are beach hotels and the percentage of city hotels is 35 percent.

\section{Methodology}

The study intends to assess the present status in relation to receipt of environmental awards and certifications, as an indicator of level of environmental management Accordingly the it covers the receipt of relevant environmental awards/certifications and other forms of recognition in relation to water, energy and waste management. The assessment is done using probit model and marginal effects. The independent variables include the characteristics of the officer responsible for environmental management, hotel characteristics, customer related variables, and performance indicators - which include average occupancy. Robust estimates were obtained and Pearson chi-square test was undertaken to measure the goodness of fit of each model.

\section{Results and Discussion}

The descriptive statistics shows that around 19 percent of the hotels have received relevant awards and certifications. Hotels in Kalutara district show the highest percentage of receipts of environmental awards and certifications (28 percent), while Gampaha district shows the lowest percentage (11 percent). In the Colombo district, the percentage of hotels which have received awards and certifications is around 22 percent.

According to the Probit results (Table 1), chain affiliation is identified as a significant variable having a positive impact on getting environmental awards and certifications. This complements the findings of previous studies. For instance, chain affiliation is found to be a significant determinant of adoption of environmental management practices in Egypt as shown by Dief and Font (2012). Accordingly, chain affiliated hotels may be having higher access to resources and information and also chain level environmental standards. 
Table 1: Probit regression results

\begin{tabular}{lcc}
\hline \multicolumn{1}{c}{ Dependent Variable } & Marginal Effect & Probability \\
\hline Size category $(0=$ small, $1=$ large $)$ & 0.100 & 0.255 \\
Luxury hotel & $0.134^{* *}$ & 0.090 \\
Classified hotel (0=unclassified, 1= classified) & 0.071 & 0.416 \\
Chain affiliation (1=chain, 0=otherwise) & $0.199 * * *$ & 0.004 \\
Percentage of customers for business purpose & -0.000 & 0.904 \\
Pearson chi square goodness of fit test estimate & \multicolumn{2}{c}{52.40} \\
Prob > chi2 & \multicolumn{2}{c}{0.3072} \\
\hline
\end{tabular}

Also, luxury hotels seemed to show a higher probability of receiving environmental awards and certifications, when compared with budget hotels and mid-range hotels. This could be because of the existing facilities in the luxury hotels.

Surprisingly, the size category of hotels or the size (number of rooms) was not statistically significant. Descriptive statistics show that the percentages of receiving environmental awards and certifications are 6 and 28 percent respectively in small and large hotels respectively.

\section{Conclusions}

The assessment shows that receipt of environmental awards and certifications in the hotels in the Western Province of Sri Lanka is primarily determined by the hotel characteristics such as luxury level and chain affiliation. Customer profiles, in terms of purpose and origin (local/foreign) were not significant determinants.

The results show that for hotels who receive assistance in regard to environmental management (through their chains, in the case of present study) are more likely to receive certifications and environmental awards which can be used in marketing their products. This calls the need for providing assistance to individual hotels in getting certifications and awards. Also, further research is required in relation to financial benefits and other probable impacts of the awards and certifications in the individual hotels and the industry in general.

\section{Acknowledgement}

This work has been undertaken with the financial support of the South Asian Network for Development and Environmental Economics (SANDEE) and its sponsors. Technical support and guidance has been provided by several SANDEE advisors and peers during the course of this research. The author also acknowledges the comments from the anonymous reviewer. 


\section{References}

Blackman, A., B. Lahiri, W. Pizer, M. R. Planter and C. M. Piña (2007). Discussion Paper, Resources for the future.

Dief, M. E. and X. Font (2012). "Determinants of environmental Management in the Red Sea Hotels: personal and organizational values and contextual variables." Journal of Hospitality \& Tourism Research, 36 (1).

Ethridge, M. A. (1998). "Measuring environmental performance: a primer and survey of metrics." In Global Environmental Management Initiative (GEMI), Washington D.C., USA.

Gil, M. J. A., J. B. Jiménez, J. J. C. Lorente (2001). “An analysis of environmental management, organizational context and performance of Spanish hotels". Omega, 29 (6), 457 - 471.

Khanna, M. and C. Speir (2007). "Motivations for proactive environmental management and innovative pollution control." Selected paper prepared for presentation at the American Agricultural Economics Association Annual Meeting, Portland, OR, July 29 - August 1, 2007.

Klassen, R. D., C. P. McLaughlin (1996). “The impact of environmental management on firm performance.” Management Science, 42 (8), 1199 - 1214.

Mamingi, N., S. Dasgupta, B. Laplante and J. H. Hong (2008). "Understanding firms' environmental performance: does news matter?." Environmental Economics and Policy Studies, 9 (2).

Rivera, G. (2002). "Assessing a voluntary environmental initiative in the developing world: the costa Rican certification of sustainable tourism." Policy Sciences, 35: 333-360.

Segarra-Oña, M., A. Peiró-Signes, R. Verma and L. Miret-Pastor (2012). "Does environmental certification help the economic performance of hotels? Evidence from the Spanish hotel industry." [Electronic version]. Cornell Hospitality Quarterly, 53(3): 242-256.

UNWTO (2011). UNWTO Tourism Highlights. 